\title{
SILVESTRE ABARCA. UN INGENIERO MILITAR AL SERVICIO DE LA MONARQUÍA HISPANA
}

\section{PEDRO CRUZ FREIRE}

Sevilla, Athenaica, 2017, 434 páginas

ISBN: 978-84-17325-14-5

Los estudios sobre historia de la ingeniería y de los ingenieros en la américa española gozan en la actualidad de enorme vigencia. Como disciplina de la historia del arte, estos trabajos permiten documentar y valorar un legado patrimonial de enorme riqueza con implicaciones que, al mismo tiempo, trascienden sus valores estéticos y funcionales. En este sentido, el patrimonio militar y civil de los ingenieros se inscribe como testimonio de la capacidad y eficacia de la administración por gestionar un territorio que escapaba al entendimiento del hombre europeo hasta 1492; al tiempo, sus fortificaciones hablan de cómo se fraguaron las relaciones geoestratégicas de las principales potencias europeas y de cómo la lucha por el control — comercial principalmente- del continente americano acabó dando forma al origen de las naciones actuales. Este es el discurso que en parte ha sostenido la labor investigadora en los últimos años de una serie de proyectos de investigación que ha dirigido el Dr. Alfredo J. Morales con el apoyo financiero de los ministerios de Economía y Competitividad y de Ciencia, Innovación y Universidades. Estos proyectos han dado como resultado en los últimos años una serie de publicaciones enmarcadas, en muchos casos, en su ámbito formativo doctoral. Un ejemplo de ello es el libro del Dr. Pedro Cruz Freire que aquí se reseña y que es el resultado de su labor como investigador predoctoral FPI del proyecto de I+D "Arquitecturas dibujadas. Ingenieros militares en Cuba (1764-1898)" (HAR201125617) adscrito al Departamento de Historia del Arte de la Universidad de Sevilla.

El libro "Silvestre Abarca. Un ingeniero militar al servicio de la monarquía hispana" se inscribe en una de las líneas del citado proyecto, concerniente a la documentación biográfica de los principales ingenieros militares que contribuyeron a la gestión territorial y defensiva de la América española. En concreto, el trabajo del Dr. Cruz tiene como protagonista al ingeniero militar del siglo XVIII Silvestre Abarca, una de las personalidades de mayor importancia y trascendencia de la historia del Real Cuerpo de Ingenieros Militares. 
Para comprender la dimensión y el contexto de la obra de Abarca, el Dr. Cruz inicia su trabajo con una introducción histórica en donde se abordan los conflictos que acotaron las relaciones geoestratégicas y diplomáticas de las potencias europeas a lo largo del siglo XVIII. Con ello se entiende mejor la necesaria reforma en la administración del ejército que condujo a la creación del Real Cuerpo de Ingenieros Militares, cuyo proceso de formación y gestión es analizado. Ello sienta las bases para entender algunos aspectos biográficos con los que se introduce a Abarca al final de este primer capítulo.

Las amplias y complejas competencias que fue adquiriendo este ingeniero en el seno del Cuerpo de Ingenieros son desarrolladas en el segundo capítulo de la monografía a través de la documentación de múltiples comisiones. Así se entiende cómo, a través de ellas, Abarca fue modelando su figura como ingeniero ocupado de labores tanto propiamente castrenses, con desempeños destacados en las campañas de Italia, como civiles, actuando en la coordinación de los trabajos en las minas de azogue de Almadén y en la proyección del Canal de Castilla.

Esta faceta doble del ingeniero entre lo militar y lo civil se mantiene con una significación si cabe mayor en el periodo de siete años en el que Abarca estuvo destinado en Cádiz. Su estatus de puerto y puerta de la América hispana adquirido tras el traslado en 1717 de la Casa de la Contratación redefinió la ciudad como una de las principales plazas de la Corona. Como consecuencia, ésta fue objeto de importantes reformas en su sistema fortificado en las que Abarca tomó partido, según se analiza y documenta en el capítulo tercero de la monografía. Así, resultan fundamentales sus trabajos en el frente de tierra de la ciudad y en el trazado abaluartado de su muralla costera. Al mismo tiempo, Abarca desempeñaría importantes comisiones para dotar a la administración de espacios y edificios como fueron el del Consulado, la Casa de la Contratación, la Aduana y más significativamente el Pabellón de Ingenieros.

Este bagaje será el que le acompañe a una de las principales comisiones de su vida profesional que lo llevará a La Habana para coordinar los trabajos de fortificación de la isla de Cuba después del duro golpe que supuso su toma y ocupación por los británicos en 1762. El Dr. Cruz logra documentar con precisión el alto grado de responsabilidad de Abarca en la actualización del trazado defensivo cubano y más particularmente habanero, al que dotó de nuevas fortificaciones, de las que destaca el fuerte de San Carlos de la Cabaña como su principal aportación, valorado hoy como uno de los grandes hitos de la ingeniería militar 
española. Esta y otras muchas obras y proyectos tienen el interés de formar parte de un coherente Plan de Defensa integral que asimismo requirió de la participación de un importante equipo de ingenieros que trabajaron conjuntamente bajo la coordinación de Abarca. Así se entiende cómo el ingeniero consiguió intervenir en el conjunto de la isla con obras de fortificación en Matanzas, Baracoa o Santiago de Cuba, documentadas con detalle por el Dr. Cruz.

El recorrido biográfico se cierra en el capítulo cinco con el análisis de sus últimos diez años de vida coincidentes con su vuelta a la península. Aquí se hará cargo, después de la reestructuración administrativa del Cuerpo de Ingenieros, de su Ramo de Fortificaciones, lo que da cuenta del grado de autoridad adquirido por Abarca como figura indiscutible del ejército español. Particularmente destaca su interés en revertir la situación de desasistencia del vasto territorio americano para el que propone una dotación de ingenieros estable, preparada y organizada. El capítulo se cierra con otras intervenciones en la supervisión de proyectos defensivos en Ceuta, Veracruz, Acapulco o Cartagena de Indias, así como con su participación en campañas militares como las de Argel y Gibraltar.

Ayuda a la compresión del conjunto del texto una selección bien escogida de ilustraciones de las que destacan planos inéditos que permiten dar una dimensión visual al análisis de la documentación de archivo aportada. Esta es la que, junto a la bibliografía citada, soporta el valor científico de este libro que resulta una aportación fundamental para concluir, por primera vez, una visión cerrada y global de este personaje capital de la ingeniería militar española.

Ignacio J. López Hernández

Universidad de Almería 